\title{
LEPROSY and LUNG LESIONS
}

A Report on Investigation of Three Cases by a Differentiating Stain: "Sudan Black"

by Dr. B. B. Gokhale, Miss Usha OAK, DR. S. M. WABLE.

of Sassoon Hospitals, Poona, Bombay State, India

Diversity of opinion exists on the subject of the etiology of lesions of the lung in leprosy. Some workers think that the lesions are due to $M$. leprae; others feel that they are due to M. tuberculosis.

Sticker (1905) expressed his opinion thus: Leprosy may affect the lung in any form, from that of chronic peri-bronchitis to caseous pneumonia, in which case it may resemble tuberculosis. There may be no minute changes though bacilli may abound.

Babes (1906) put forward the theory that varying degrees of lung lesions may be present in leprosy patients. His evidence in favour of these lesions and their differentiation from tuberculous lesions depended on the arrangement and the morphological characteristics of the two organisms.

Sagai-Masaki (1917) stated that, in leprous patients, tuberculosis is a primary and leprosy a secondary lesion of the lungs. Yet, he mentioned finding leprous nodules in the pleura.

The observations of Kobayashi (1929) were based on the autopsies of the lungs of leprous patients. "In 32 out of 60 cases he found tubercle bacilli and pathological changes of a tubercular nature. He found lepra bacilli in 19 out of these 60 cases. In 8 out of the 32 tubercular lungs and in 11 out of the 28 non-tubercular lungs he found lepra bacilli".

E. Muir (1933) drew his conclusions from his experiments on guinea pigs who were inoculated with A.F.B. positive sputum. He also depended on the clinical signs in the lungs. He opined that the lung lesions in the 9 cases he recorded were due to leprosy.

Ranade and Gokhale (1954) published a report on 8 cases of leprosy with lung lesions. They concluded that in 7 of these cases the lung lesions were due to leprosy and in one case due to tuberculosis.

Hansen and Looft (1895) denied the existence of leprosy of the lungs. They stated: "There exists a sharp anatomical distinction between leprosy and tuberculosis and there is no such thing as leprosy of the lungs". To establish a differential diagnosis, they recommended a thorough examination of the bronchial glands.

Wise (1912) tried to clarify the facts by experiments made on guinea pigs. A small portion of the lung tissue of patients with A.F.B positive sputum was removed and pocketed in the thigh of the guinea pig. He based his comments on the post-mortem findingsmacroscopic and microscopic:- "The disease was well advanced 


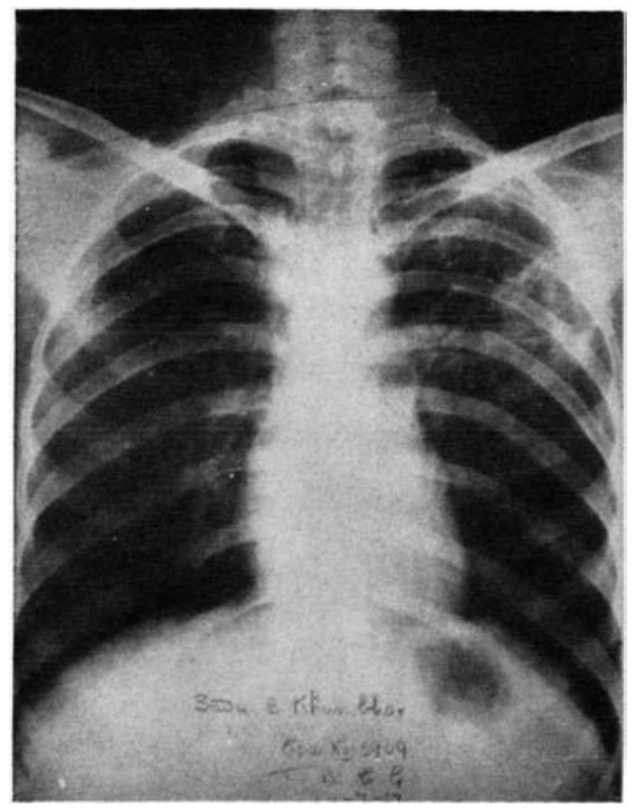

Plate No. 1 (1954)

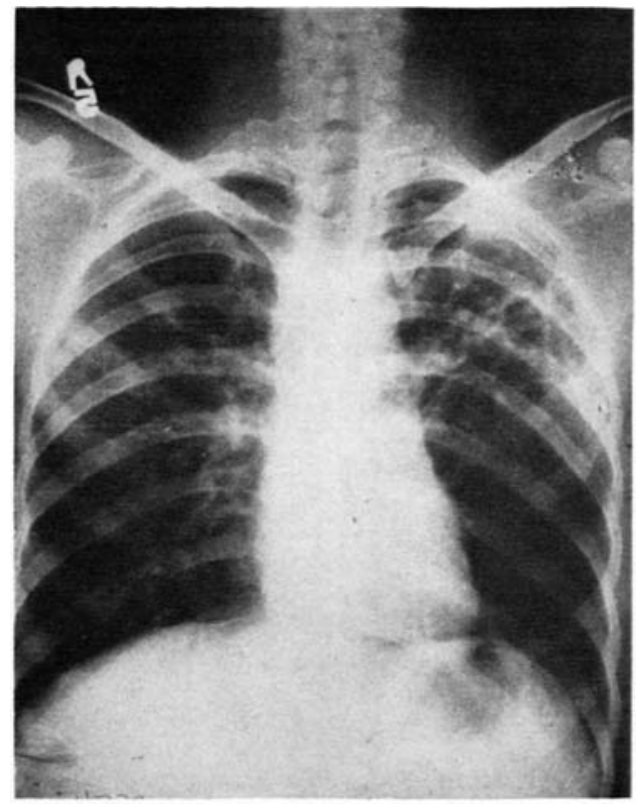

Plate No. 2 (4.7.58)

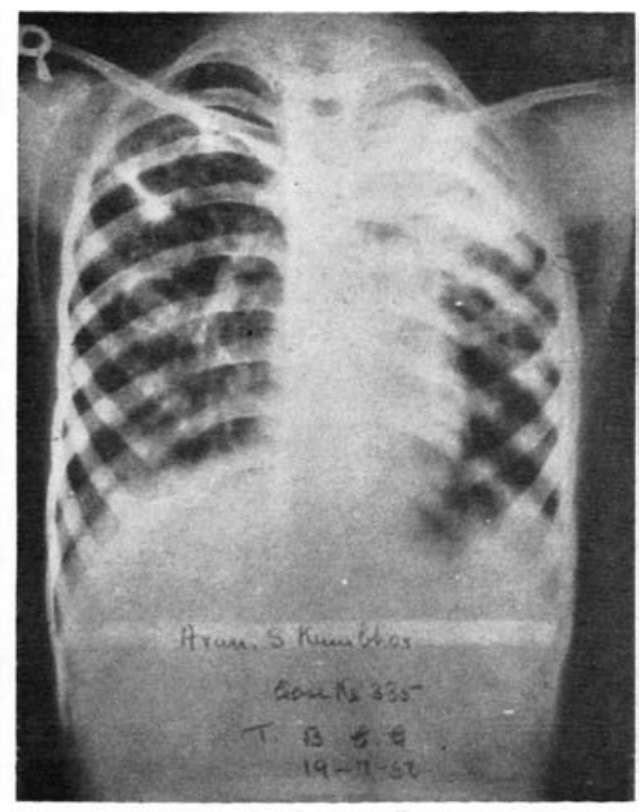

Plate No. 3. (S.S.K.'s son)

CASE No. 1 (S.S.K.) Compared to first skiagram (pl. No. 1-1954) there are now, 4.7 .58 ( $p l$. No. 2). increased number of nodular lesions in left upper lobe, with presence of streaky fibrotic strands. A definite cavitation is seen near the anterior end of eleventh rib. A few nodular lesions strands. A definite cavitation is seen near the anterior end of eleventh rib. A few'
are seen ight upper lobe, with some thickening of minor inter-lobar fissure.

Findings are consistent with pulmonary tuberculosis. 


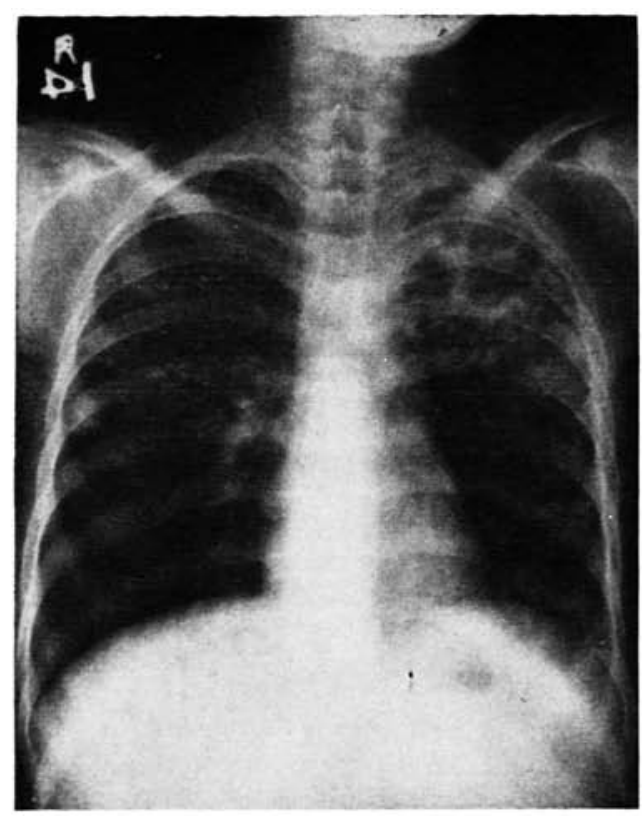

Plate No. 4

(S.G.) CASE No. $2 \quad$ (4.7.58) Nodular infiltration of the entire left lung and right mid-zone, with cavitations in left infra-clavicular region. A few nodular lesions are also seen in right upper lobe.

Findings are consistent with pulmo-

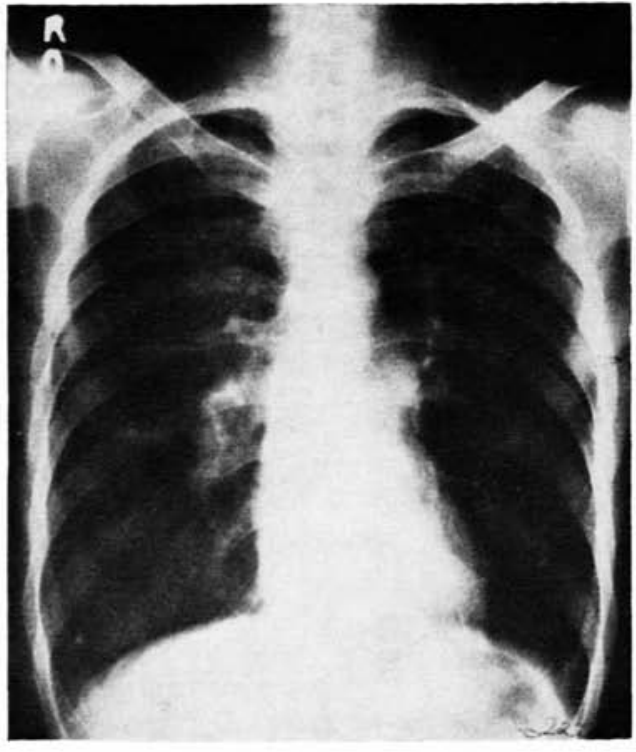

Plate No. 5

(L.B.K.) CASE No. $3 \quad$ (4.7.58) Both lungs are markedly emphysematous. Pulmonary segment is prominent with engorged pulmonary hilar vessels Cardiac apex is slightly elevated, sugCardiac apex is slightly elevated, sug-
gesting right ventricular enlargement. Findings indicate pulmonary emphysema with cor pulmonale.

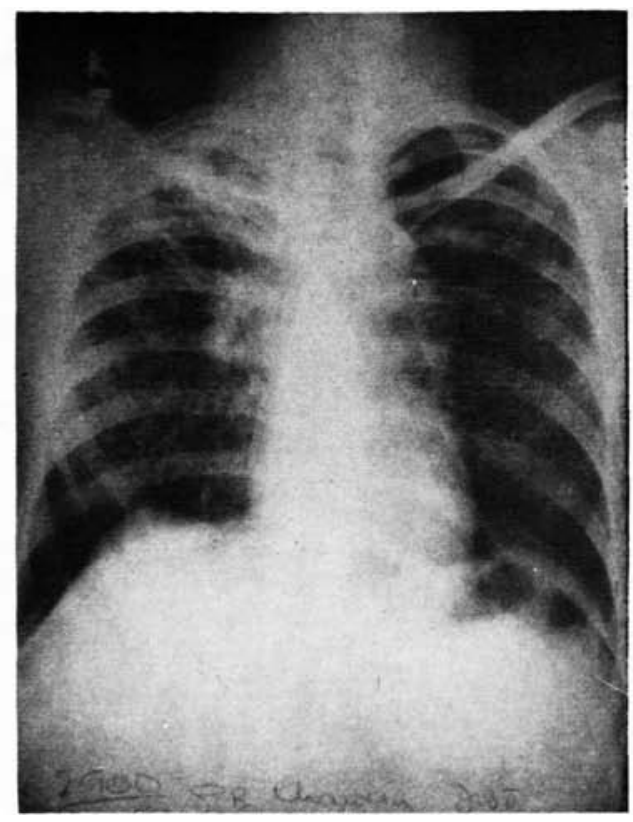

Plate No. 6

(G.B.K.)

CASE No. 4

Infiltration of the lungs with cavitation at the apex of the right lung.

Findings are consistent with pulmoary tuberculosis. 
when death occurred and the lung lesions, which were certainly recent in origin, resembled more of a final general dissemination than of a natural sequence of leprosy".

Wade (1927) denied the presence of lung lesions in leprosy. His observations were from numerous post-mortems he had done on patients who died of leprosy.

In the absence of a definite positive proof, the observations were more or less speculative.

Chaussinand and Viette have described a method of staining, enabling the differentiation between $M$. tuberculosis and M. leprae.

We decided to take advantage of this method in our work on lung lesions in leprosy:

\section{Material and Method}

A 24 hours collection of sputum of patients was made in a clean glass container.

A specimen for preparation of a slide was picked from this collection and a smear made as usual.

A portion of the sputum was concentrated as for M. tuberculosis by Petroffe's method, and smears were made from this concentrated material.

The slides were then fixed by heat. One set was stained as usual by Ziehl Neelsen method, and the other by Sudan Black as below:

Seventy per cent alcoholic solution of Sudan Black was poured on the slide and the stain was burnt till emitting a blue flame.

The slide was then washed on both sides first with water, and next with acetone for 2 to 5 minutes.

It was counterstained with safranin and finally washed with water again.

By this method, $M$. tuberculosis takes up the stain, but $M$. leprae remains unstained.

Material aspirated at the time of bronchoscopy was also examined microscopically.

Case No. 1:

\section{CASE REPORTS}

A male S.S.K. (a pottery maker) aged 36 years, was first seen 4 years ago when he complained of tingling and numbness in the extremities and cough with expectoration. At that time his sputum was examined and an X-ray plate (Plate No. 1) taken. The sputum showed A.F.B. He was treated with diamino-diphenylsulphone.

Clinically, he is a case of tuberculoid type of leprosy. Two months ago, he was admitted as in-patient in the hospital on account of an attack of haemoptysis.

His family history showed that his son, aged 12 years, had a hypopigmented anaesthetic patch on the right cheek. The boy was under treatment for leprosy for one year. He also had lung lesions (X-ray plate No. 3). Last year, he was admitted in the hospital for prof use haemoptysis and he expired.

Present condition of the patient: Facial and palmar erythema with two hypopigmented anaesthetic patches in the lumbar region. The supratrochlear glands are palpable. (X-ray plate No. 2) shows a cavity at the left apex. 
(a) Blood:

\section{Investigations}

1. $\mathrm{Hb}-9$ gms. $\%$

2. R.B.C.'s - $3.1 \mathrm{mill} . / \mathrm{cu} . \mathrm{mm}$.

3. W.B.C's - 6200/cu.mm.

4. Diff. $\mathrm{P}-64 \%$

$\mathrm{L}=27 \%$
$\mathrm{E}=2 \%$
$\mathrm{M}-7 \%$

$\mathrm{B}$ - nil

5. E.S.R. - 45 after 1 hour

6. P.C.V. - 42 parts $\%$

7. V.D.R.L. - negative.

(b) Urine: nothing abnormal detected.

(c) Local smears: negative for M. Leprae.

(d) Laryngoscopy (done on 3/6/58): larynx and pharynx normal.

(e) Radiogram of the chest: A.P. view (X-ray plate No. 2).

( $f$ ) Sputum: smears positive by Ziehl Neelsen and Sudan Black stains. Culture reports of both these cases are positive for $M$. tuberculosis.

\section{Case No. 2:}

A male S.G. aged 20 years started developing hypopigmented and erythematous patches on his body eight years back. Since one year, he also has got cough with expectoration.

Clinically, he is diagnosed as a case of dimorphous type of leprosy.

He was admitted as an in-patient $1 \frac{1}{2}$ years ago, and is under treatment since then for leprosy.

On clinical examination, the patient shows hypopigmented anaesthetic and erythematous patches all over. There is loss of hair of the eyebrows. The ulnar nerves are thickened. The ear lobules show thickening. (X-ray plate No. 4).

(a) Blood

\section{Investigations}

1. $\mathrm{Hb}-8$ gms. $\%$.

2. R.B.C.'s -2.75 mill./cu.mm.

3. W.B.C.'s - 6400/cu.mm.

4. Diff. P $-56 \%$

$$
\begin{aligned}
& \mathrm{L}=36 \% \\
& \mathrm{E}=1 \% \\
& \mathrm{M}=7 \%
\end{aligned}
$$

5. E.S.R. $\quad-55$ after 1 hour. Corrected to 34

6. V.D.R.L. - weakly positive

(b) Urine: Nothing abnormal detected.

(c) Smears from the patches: negative for M. leprae.

(d) Laryngoscopy (done on 3/6/58): nothing abnormal detected.

(e) Radiogram of the chest: A.P. view (X-ray plate No. 4)..

(f) Sputum: smears positive by Ziehl Neelsen and Sudan Black stains.

Result of culture for $M$. tuberculosis is negative. (Loffler's egg medium).

Repetition of culture has been requested.

\section{Case No. 3:}

A male L.B.K. aged 32 years is a tailor. He first noticed signs of the disease ten years back. He has widely distributed lepromatous lesions.

He was admitted as an in-patient one month ago, for breathlessness.

Clinically, he is a case of lepromatous type. He complains of tingling and numbness in the extremities, as well as cough with expectoration. The ulnar nerves are thickened on both sides.

This patient has been taking anti-leprosy treatment off and on. 
(a) Blood:

\section{Investigations}

1. $\mathrm{Hb}-12$ gms. $\%$

2. R.B.C.'s - $4.1 \mathrm{mill} . / \mathrm{cu} . \mathrm{mm}$.

3. W.B.C.'s - 7800/cu.mm.

4. Diff. $P-30 \%$

$$
\begin{aligned}
& \mathrm{L}-62 \% \\
& \mathrm{E}-4 \% \\
& \mathrm{~B}-1 \% \% \\
& \mathrm{M}-3 \%
\end{aligned}
$$

5. E.S.R. $-28 \mathrm{~mm}$. after 1 hour corrected to $25 \mathrm{~mm}$.

6. P.C.V. - 45 parts $\%$

7. V.D.R.L. - strongly positive.

(b) Urine: nothing abnormal detected.

(c) Smears for the lesions: positive for M. leprae.

(d) Laryngoscopy: (done on 20/6/58) larynx and pharynx normal.

(e) Radiogram of the chest: A. P. view (X-ray plate No. 5).

(f) Sputum: smears positive by Ziehl Neelsen and Sudan Black stains. Culture reports of both these cases are positive for $M$. tuberculosis

Case No. 4:

A male G.B.C. aged 37 years, was admitted as in-patient for haemoptysis for four days.

This patient was irregularly attending the out-patients department of these hospitals for the last few years. He was being treated with diamino-diphenylsulphone.

His sputum was examined and an X-ray plate taken (plate No. 6).

Clinically he is a case of tuberculoid type of leprosy. He has got hypopigmented anaesthetic patches on the body. Ulnar nerves on both the sides are thickened

\section{Investigations}

The patient left the hospital against advice, a short while after admission, and therefore the laboratory investigations are not complete.

(a) Local smears: negative for M. leprae.

(b) Sputum smears: positive by Ziehl Neelsen and Sudan Black stains.

(c) Radiogram of the Chest: A.P. view (X-ray plate No. 6).

\section{Summary}

In the three cases described here, $M$. tuberculosis has been demonstrated in the sputum.

With this small report, it is hoped that other workers would report similarly, so that sufficient material may be available for proper elucidation.

\section{Acknowledgments}

Our thanks are due to: Dr. M. S. Dikshit, Department of Radiology, Sassoon Hospitals, Poona; to Mr. V. N. Joshi, artist, B.J. Medical College, Poona; and the Department of Pathology, Poona, for the co-operation they have given us.

Thanks for the encouragement and help received all along from colleagues and friends. 


\section{REFERENCES}

BABES (1906). Kolle u Wasserman.

Chaussinand. Text-book of Leprosy. (In French).

HANSEN and LOOFT. (1895). Leprosy in its Clinical and Pathological aspects. John Wright \& Co., Bristol.

Kobayashi. (1929). Uber die viscerale Lepra. Universitas Imperialis in Kyoto.

Muir, E. (1933). Leprosy of the Lungs, Leprosy in India, 5, 72, 1933.

RANADE, S. N. and Gokhale, B. B. (1954). Lung lesions in Leprosy. Journal of the Association of Physicians of India, Vol. I, No. 3, p. 36-42.

Sagai-MaSaKi. (1914). Lungen Lepra und ihre Haufigkeit. Igaku-Chuo Zassi, Nr. 188. S. 18.

Sticker. (1905) G. Handb. D. tropenkr. Bd. 11, Art "Lepra”, P. 189.

WADE and Rodriguez. (1927). A description of Leprosy: its etiology, pathology, diagnosis and treatment.

WisE, K. S. (1912). Lung Lesions in Leprosy. Jnl. School, Trop. Med., London, Vol. I, p. 251. 